\title{
Notas sobre o campo da Sociologia do Esporte: o dilema da produção científica brasileira entre as Ciências Humanas e da Saúde
}

\author{
Ana Leticia Padeski Ferreira* \\ Juliana Vlastuin ${ }^{* *}$ \\ Tatiana Sviesk Moreira*** \\ Cristina Carta Cardoso de Medeiros ${ }^{* * * *}$ \\ Wanderley Marchi Junior ${ }^{* * * *}$
}

\begin{abstract}
Resumo: O objetivo deste artigo é apresentar os critérios de avaliação vigentes no ano de 2010 para a produção e divulgação científica na área da Educação Física e da Sociologia discutindo as lógicas que afetam os pesquisadores da Sociologia do Esporte. Quando consideramos uma disciplina de fronteira, como é o caso da Sociologia do Esporte, percebemos que os objetos de estudo se encontram entre as Ciências Sociais e da Saúde, acarretando o enfretamento de duas situações: a dificuldade de inserção de trabalhos nos periódicos da Sociologia e os baixos escores da linha de pesquisa nas revistas da Educação Física.

Palavras-Chave: Educação Física, Sociologia, Sociologia do Esporte, Produção e avaliação de conhecimento científico.
\end{abstract}

\footnotetext{
"DECISO - CEPELS - ALESDE - UFPR/ Faculdade Guairacá, Curitiba, PR, Brasil E-mail: analeticiaferreira@gmail.com

"DECISO - CEPELS - ALESDE - UFPR / Unicentro, Curitiba, PR, Brasil, vlastuin6@yahoo.com.br "*DEF - CEPELS - ALESDE - UFPR, Curitiba, PR, Brasil E- mail: tatisviesk@hotmail.com

...'DEF - CEPELS - ALESDE - UFPR, Curitiba, PR, Brasil. E-mail: cricaccm@gmail.com

"..*tDEF - DECISO - CEPELS - ALESDE - UFPR / WVU, Curitiba, PR, Brasil. E-mail: wmarchijr@gmail.com
} 


\section{INTRODUÇão}

As possibilidades de estudos científicos do esporte na área de Ciências Biológicas e Sociais têm colocado a Sociologia do Esporte brasileira em uma busca constante por consolidação e autonomia perante os campos da Educação Física e da Sociologia. Uma passagem contida na apresentação do livro Educação Física \& Esportes, organizado por Wagner Wey Moreira, perspectiva as possibilidades de estudos científicos da área da Educação Física e dos esportes no início da década de 90, corrobora com o argumento colocado. O cenário que se apresentava era o seguinte:

As décadas de 70 e 80 caracterizaram-se por importantes modificações no quadro da Educação Física brasileira. Passamos de uma situação onde verdades absolutas eram transmitidas para, através da reflexão crítica, adentrarmos em um período de crise (entendida aqui como uma oportunidade de mudança). Nessa passagem muito foi dito e escrito, o que nos permite afirmar que a produção teórica dessas duas décadas suplanta, qualitativa e quantitativamente, tudo o que já vinha sendo redigido na área da Educação Física e dos esportes (MOREIRA, 1992, p. 9).

Ainda que desatualizado, o quadro indica uma direção que apresenta indicativos de mudanças na Educação Física, a do avanço qualitativo e quantitativo. $\mathrm{O}$ elemento determinante das alterações de tal quadro foi o sistema de pós-graduação que se consolidou no Brasil (PILATTI; MARCHI JÚNIOR; VLASTUIN, 2009). A Educação Física, na esteira das mudanças em curso, adentrou no sistema apesar da falta de tradição acadêmica e de problemas históricos como recursos financeiros escassos e autonomia limitada de temas e métodos.

A inserção, ainda que de forma insipiente, ocorreu na década de 1980 e foi marcada pela tentativa tardia da área na definição de seu objeto de estudo e, por extensão, na obtenção do status científico, 
principalmente com a importação de teorias desenvolvidas em centros mais avançados. Trata-se de um processo irrompido de múltiplas formas: João Paulo Medina (1992), prognosticou a necessidade da Educação Física entrar em um período de crise; autores como Go Tani, Valter Bracht, Mauro Betti, Hugo Lovisolo, Silvino Santin, Adroaldo Gaya, Apolônio A. do Carmo, apenas para citar alguns, aderiram ao debate; as reflexões do norte-americano Henry, dos franceses Pierre Parlebás e Jean Le Boulch e, principalmente, do filósofo português Manuel Sergio permearam o meio acadêmico, dando o tom das discussões. Ocorre uma espécie de "neurose coletiva" na área em busca de sua identidade.

A elaboração dessa identidade não aconteceu. A "crise", ou a oportunidade de mudança, como prefere Moreira (1992), chegou e foi embora sem produzir transformações decisivas, a não ser, talvez, uma mudança de atitude nos pesquisadores. Com o desvanecer das discussões, um novo cenário passou a fazer parte da Educação Física: o da pós-graduação.

Falar em pesquisa científica implica em inscrever as discussões em um tipo específico de conhecimento: o científico. Para Marconi e Lakatos, "a complexidade do universo e a diversidade de fenômenos que nele se manifestam, aliadas à necessidade do homem de estudálos para entendê-los e explicá-los, levaram ao surgimento de diversos ramos de estudos e ciências específicas" (MARCONI; LAKATOS, 2000, p. 25).

Na literatura da área de metodologia, a questão da classificação e divisão da ciência é pautada em diferentes critérios, o que, em termos práticos, determina a existência de diversas classificações. No presente texto adotou-se a classificação proposta por Marconi e Lakatos (2000, p. 28): 


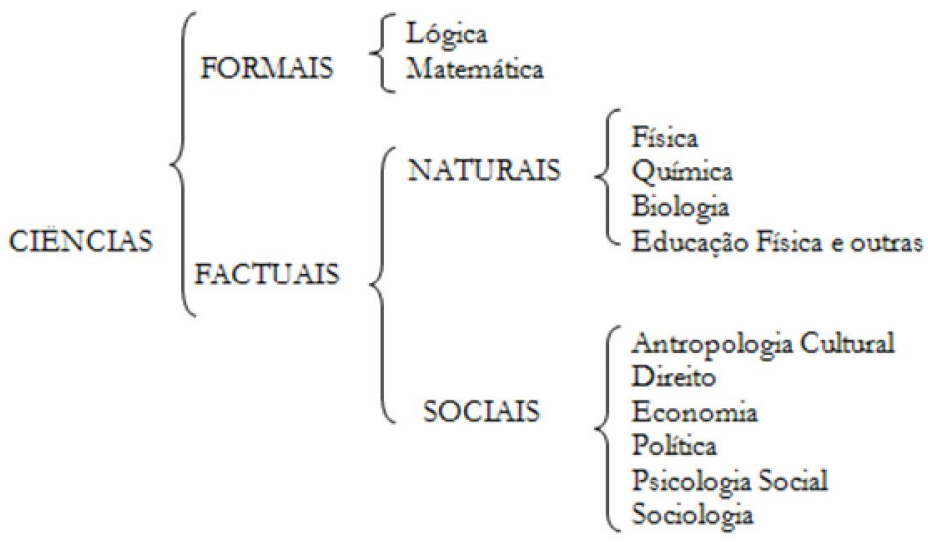

Figura 1 - Classificação e Divisão da Ciência

Fonte: Marconi e Lakatos (2000)

Neste modelo, a Educação Física e a Sociologia são alocadas dentro das Ciências Factuais, mas a Educação Física nas Naturais e a Sociologia nas Sociais. Porém, é possível afirmar que a produção da Educação Física ocorre tanto no campo natural como no social. O que poderia ser lido como fator agregador para o desenvolvimento da área, o fato de ambas serem classificadas nas Ciências Factuais, tem produzido linhas de pesquisa que sofrem ao mesmo tempo diferentes critérios de avaliação científicos e de status.

Esse é o caso da Sociologia do Esporte que por situar os objetos de estudo entre as Ciências Sociais e Naturais, enfrenta duas situações: a dificuldade de inserção de trabalhos nos periódicos da Sociologia e os baixos escores da linha de pesquisa nas revistas da Educação Física, disputando espaço com as pesquisas das Ciências Naturais, apesar das condições de produção diferenciadas.

Esse objeto de estudo, o esporte, tem suscitado nas últimas décadas a curiosidade dos pesquisadores de várias áreas, dentre elas a Sociologia. Com maior visibilidade a partir da década de 1970, o tema atraiu interesse por suas relações mercadológicas, políticas, 
sociais, econômicas e midiáticas, dentre outras. Com esse cenário favorável, as pesquisas sobre o esporte sob um olhar sociológico tiveram um significativo crescimento na década de 1990 (TOLEDO, 2001).

Pesquisadores envolvidos com a temática se propuseram a apresentar e analisar esse espaço de discussão do esporte, sendo esses estudos iniciativas pioneiras. Apresentamos algumas pesquisas recentes que procuram delimitar essa área, como o texto de Marchi Júnior e Cavichiolli (2008). Os pesquisadores apresentam uma intenção de diagnóstico dos trabalhos que versam sobre a temática, sugerindo uma forma de realizar esse trabalho de busca e classificação de tais obras, elencando as concepções, perspectivas e objetos de estudo dessas pesquisas.

O primeiro capítulo do livro de Murad (2009) também compõe o cenário do campo da Sociologia do Esporte, explicitando a relação da área da Sociologia, em que realizou sua formação, com a de Educação Física. Também é abordado o crescente interesse pelo estudo do esporte, dada a sua aproximação com as esferas social, econômica e política, por exemplo.

Medeiros e Godoy (2009) contribuem para nossa compreensão do campo da Sociologia do Esporte ao realizar o estudo em que mapeiam os artigos publicados na Revista Brasileira de Ciências do Esporte, no período de 1979 a 2007. As autoras selecionaram as pesquisas que referenciaram as obras de Pierre Bourdieu e Norbert Elias e verificaram como esses dois sociólogos, que forneceram subsídios para a análise do esporte, foram utilizados nos textos selecionados a partir da análise de conteúdo.

Complementando nossa visão sobre as relações estabelecidas pela Sociologia do Esporte com outras áreas, destacamos o estudo de Gastaldo (2010) que se propõe a abordar a configuração política das pesquisas de cunho sociológico sobre o esporte em três áreas específicas: Comunicação, Ciências Sociais e Educação Física. O autor corrobora com a premissa dos demais estudiosos de que a incursão do esporte nas Ciências Sociais é recente e afirma que o 
campo acadêmico daí derivado data do início da década de 1980 . Para ilustrar tal fato, o estudioso elenca uma série de dados, tais como grupos de pesquisa, grupos de trabalho e associações.

O artigo de Souza e Marchi Júnior (2010) complementa o cenário posto nessa introdução ao traçar um panorama histórico e sociológico da Sociologia do Esporte no cenário mundial. Especificamente sobre o cenário brasileiro, os autores sugerem três vias de desenvolvimento do referido campo: a Sociologia do Futebol, a Teoria Crítica do Esporte e a História das Práticas Esportivas, elaborando um contexto geral que explicita as principais vertentes teóricas e os autores nelas envolvidos.

Assumpção et. al.(2010) contribui para o delineamento da Sociologia do Esporte com seu texto que aponta alguns dos temas tratados por essa área de estudo. Temáticas como a compreensão do papel e da função do esporte na sociedade moderna, o consumo de práticas esportivas, o surgimento e difusão de esportes em diferentes sociedades, as relações de gênero no espaço esportivo, as questões étnicas e raciais, desigualdades sociais e o esporte, a influência da mídia sobre o esporte e vice-versa, dentre outros objetos são preocupação dos pesquisadores da área.

Ao analisar o cenário da América Latina no início de sua produção sobre a Sociologia do Esporte e retomando suas considerações no momento atual, Alabarces (2011) nos permite perceber as mudanças que esse objeto de estudo sofreu: de um tema marcado pela pouca legitimidade e pela ausência de publicações outrora, atualmente possui um número representativo de pesquisadores nos países latino-americanos e conta com uma produção de crescente quantidade e qualidade. $\mathrm{O}$ autor também ressalta a aproximação da área com as Ciências Humanas, o que contribuiu para essa modificação na concepção do objeto e do nicho de pesquisa.

Neste cenário de produções, o objetivo desse texto é propor uma discussão inicial, ao localizar elementos e indicadores que orientam os critérios de pesquisa em ambas as áreas, bem como 
identificar as condições de produção e de divulgação da Sociologia do Esporte no trâmite de avaliação vigente no ano de 2010, além de verificarmos as diretrizes de órgão de fomento à pesquisa no Brasil e o regimento de uma instituição de ensino superior atestando a obrigatoriedade da publicação científica no meio acadêmico. Para tanto, fizemos um levantamento dos periódicos das áreas de Sociologia e Educação Física em que é possível submeter um artigo que trata sobre a Sociologia do Esporte.

Optamos por analisar o escopo das revistas excluindo as que são voltadas para publicações que se restringem ao aspecto biológico e outras temáticas pré-definidas que não permitem a inserção da Sociologia do Esporte. No entanto, tais parâmetros não garantem que nos periódicos elencados seja realmente possível a incursão de artigos científicos que focalizem os aspectos sociológicos do esporte.

Para a seleção dos artigos adotamos os seguintes critérios: (1) o mapeamento dos periódicos publicados no ano de 2010; (2) os textos devem estar publicados em periódicos das áreas de Sociologia e Educação Física; (3) tais periódicos pertencem aos estratos A1, A2, B1 e B2 do Qualis ${ }^{1}$, (4) devem tratar como tema central o Esporte ${ }^{2}$ pelo viés sociológico e (5) os artigos devem ser originais e de revisão, excluindo-se ensaios, editoriais e resenhas. Por se caracterizar como uma abordagem inicial do tema - esse levantamento é parte de um projeto de pesquisa mais amplo que procura analisar a constituição do campo da Sociologia do Esporte no Brasil através das produções da área (artigos, dissertações e teses), localização e visão dos agentes, bem como o processo de institucionalização que essa nova

\footnotetext{
${ }^{1} \mathrm{~A}$ avaliação Qualis consiste em uma lista de periódicos utilizados para a divulgação da produção intelectual dos programas de Pós-graduação. Estes periódicos são classificados quanto ao âmbito de circulação, sendo eles locais nacionais e internacionais, e quanto ao impacto de tais publicações aos quais são atribuídos os conceitos A1, A2, B1, B2, B3, B4, B5 e C. Este índice fundamenta o processo de avaliação do Sistema Nacional de Pós-graduação Tais informações foram obtidas em (COORDENAÇÃO DE APERFEIÇOAMENTO DE PESSOAL DE NÍVEL SUPERIOR, 2011b).

${ }^{2}$ Dada a necessidade de estabelecer o significado da palavra esporte e sabendo dos riscos de reduzir um fenômeno polissêmico (BETTI, 1998), adotamos o seguinte conceito: atividades físicas construídas e determinadas por elementos históricos, sociais e culturais em processo de profissionalização, mercantilização e espetacularização que não se restringe somente às modalidades institucionalizadas (COAKLEY, 2010; MARCHI JUNIOR; CAVICHIOLLI, 2008).
} 
área vem sofrendo -, ele não se propõe a realizar nesse momento um diálogo com as produções mapeadas, mas sim delinear a incidência dessas publicações nos periódicos dos estratos mencionados. Também é válido destacar que existem produções da Sociologia do Esporte que não foram contempladas - como por exemplo ensaios e resenhas-, pois não atendem um ou mais critérios de seleção.

Lançamos como tese que a situação da Sociologia do Esporte é a de uma área de fronteira. Tal área possui uma relação de dependência em relação à Sociologia, já que necessita de seus referenciais teóricos para a análise dos seus objetos de pesquisa. Em estado de emergência latente, tem ganhado paulatinamente espaço no campo da Sociologia devido aos fatores: (1) maior visibilidade do esporte na sociedade brasileira através da profissionalização e espetacularização, (2) aliada a uma mudança no campo da Sociologia, que ao invés de focar seus esforços em temas clássicos, vem abrindo seu leque de interesses.

Em relação à Educação Física, a Sociologia do Esporte disputa espaços com a vertente biológica desse campo, condição historicamente estabelecida em relação aos estudos das Ciências Humanas. Dada essa condição da área/disciplina, os pesquisadores não possuem tantas possibilidades de publicação como os colegas das ciências biológicas e ainda não possuem uma produção constante e consistente na Sociologia.

Em síntese, a Sociologia do Esporte enfrenta dificuldades de consolidação, em partes, dada a marginalização da temática "esporte" pelos periódicos da Sociologia e à secundaridade com a qual os assuntos sociais são tratados em detrimento aos biológicos nos periódicos de Educação Física, como será demonstrado a partir dos dados da pesquisa empírica. Entretanto, além das dificuldades elencadas, os pesquisadores da área/disciplina, assim como outros pesquisadores do campo acadêmico, lidam com a obrigatoriedade da realização de pesquisas e sua divulgação tanto para sua entrada no referido campo quanto para sua manutenção, como pode ser percebido na sequência do texto. 


\section{Sistemas de aValiação em Pós-Graduação: O lugar da produ- ÇÃO CIENTÍFICA}

Para compreender o lugar ocupado e a importância da publicação científica nos programas de Pós-graduação, bem como na carreira docente, apresentamos os instrumentos avaliativos de duas instâncias. Primeiramente trazemos o Sistema de Avaliação da Pós-graduação iniciado em 1976 pela Coordenação de Aperfeiçoamento de Pessoal de Nível Superior (CAPES), órgão de fomento que tem como premissa contribuir para o desenvolvimento da Pós-graduação e da pesquisa científica no Brasil. Para tal, estabelece os seguintes objetivos:

Estabelecer o padrão de qualidade exigido dos cursos de mestrado e de doutorado e identificar os cursos que atendem a tal padrão;

Fundamentar, nos termos da legislação em vigor, os pareceres do Conselho Nacional de Educação sobre autorização, reconhecimento e renovação de reconhecimento dos cursos de mestrado e doutorado brasileiros - exigência legal para que estes possam expedir diplomas com validade nacional reconhecida pelo Ministério da Educação, MEC;

Impulsionar a evolução de todo o Sistema Nacional de Pós-graduação, SNPG, e de cada programa em particular, antepondo-lhes metas e desafios que expressam os avanços da ciência e tecnologia na atualidade e o aumento da competência nacional nesse campo;

Contribuir para o aprimoramento de cada programa de pós-graduação, assegurando-lhe o parecer criterioso de uma comissão de consultores sobre os pontos fracos e fortes de seu projeto e de seu desempenho e uma referência sobre o estágio de desenvolvimento em que se encontra;

Contribuir para o aumento da eficiência dos programas no atendimento das necessidades 
nacionais e regionais de formação de recursos humanos de alto nível;

Dotar o país de um eficiente banco de dados sobre a situação e evolução da pós-graduação ${ }^{3}$;

Oferecer subsídios para a definição da política de desenvolvimento da pós-graduação e para a fundamentação de decisões sobre as ações de fomento dos órgãos governamentais na pesquisa e pós-graduação .

Percebemos nessa descrição que tal instituição estabelece as "regras do jogo" acadêmico e científico ao dizer o que é adequado ou não a esse espaço social através de agentes selecionados para tal tarefa. Dois processos são conduzidos por esses agentes: a Avaliação dos Programas de Pós-graduação e a Avaliação das Propostas de Cursos Novos de Pós-graduação. Para o momento, iremos nos deter no primeiro ponto.

A avaliação supracitada compreende um acompanhamento anual e outro trienal dos programas inseridos no Sistema Nacional de Pós-graduação. Com as notas de 1 a 7 tais programas "[...] obterão a renovação de 'reconhecimento', a vigorar no triênio subsequente" (COORDENAÇÃO DE APERFEIÇOAMENTO DE PESSOAL DE NÍVEL SUPERIOR, 2011). É possível notar que tal instituição possui legitimidade e autoridade no campo acadêmico e científico, a ponto de atribuir reconhecimento a determinados programas. Na avaliação trienal vários quesitos são considerados abrangendo:

"Proposta do programa (consistência, abrangência, planejamento, infraestrutura);

"Corpo docente (perfil, titulação, atividades de pesquisa e formação, captação de recursos para pesquisa);

"Corpo discente (teses e dissertações defendidas, distribuição das orientações entre os docentes, qualidade das teses e dissertações

\footnotetext{
${ }^{3}$ Tais informações foram obtidas em COORDENAÇÃO DE APERFEIÇOAMENTO DE PESSOAL DE NÍVEL SUPERIOR. 2011a.
} 
- mensurada através das publicações em periódicos, eventos e livros -, eficiência do programa na formação de mestres e doutores);

"Produção intelectual (publicações qualificadas do corpo docente, distribuição de tais publicações entre os docentes, produção técnica);

"Inserção social (impacto regional/nacional, integração com outros centros de pesquisa, visibilidade $)^{4}$.

Nesse contexto são avaliadas tanto as produções docentes como discentes para aferir a qualidade e consistência de um programa. Essas publicações são valoradas quanto ao seu impacto na comunidade científica. Tal situação leva docentes e discentes a uma busca pela inserção de suas pesquisas em periódicos de estratos altos, de maior impacto.

Mas não é somente a avaliação do programa como um todo que abrange as publicações. Pedidos de bolsa, financiamentos, concursos públicos para o preenchimento de vagas para docentes em instituições de ensino superior também pontuam tais realizações dos agentes. Sobre o ponto, Castiel, Sanz-Valero e Cyted (2007, p. 3042) afirmam:

Há um aumento considerável na disputa por recursos para a pesquisa e diminuição de recursos públicos para tanto. Um dos requisitos para aceder aos financiamentos é a demonstração da produtividade dos grupos de pesquisa, sobretudo em termos de publicação nos veículos acadêmicos de melhor reputação nos respectivos campos. Assim, a competição se estende à luta ferrenha entre artigos que buscam a ocupação de espaços editoriais - o escoadouro almejado para os resultados dos esforços investigativos, mas também da necessidade de manutenção das esferas de prestígio e influência.

${ }^{4}$ Tais informações foram obtidas em COORDENAÇÃO DE APERFEIÇOAMENTO DE PESSOAL DE NÍVEL SUPERIOR, 2011a. 
A Resolução no 10/05 - Conselho de Ensino, Pesquisa e Extensão (CEPE) ${ }^{5}$, que regulamenta as normas de concurso público da Universidade Federal do Paraná, traz exemplos da classificação das produções acadêmicas. Artigos em periódicos indexados, livros publicados, organização de livros ou coletâneas são as publicações que agregam de 20 a 50 pontos na avaliação do currículo do candidato.

Dessa forma fica clara a relevância das publicações científicas tanto no cenário do programa de Pós-Graduação quanto na carreira de cada discente e docente. Luz (2005) contribui para a discussão quando destaca que o conceito de produtividade - o qual se refere ao quantum da produção intelectual, sobretudo bibliográfica, desenvolvida em um determinado período de tempo - é necessário para manter os pesquisadores na sua posição dentro do campo científico.

Nesse contexto, adotando a expressão utilizada por Castiel, Sanz-Valero e Cyted (2007), os agentes inseridos nesse campo devem "publicar ou perecer". Tal lema:

[...] implica algo parecido com as lutas territoriais para a seleção dos mais aptos entre artigos que lutam entre si. Primeiramente, para despertarem o interesse e a atenção dos editores como tema relevante e importante no âmbito acadêmico; depois, serem devidamente analisados para obedecerem às demandas dos revisores em busca da ansiada chancela de qualidade que conduz à meta da aprovação para a publicação. Este é um prêmio depois da ultrapassagem por esses controles, pois isso significaria a possibilidade de habitar nichos mais valorizados deste mercado, algo que poderia ser chamado de "darwinismo bibliográfico" (CASTIEL; SANZ-VALERO; CYTED, 2007, p. 3046).

\footnotetext{
${ }^{5}$ A Resolução n. 10/05 do Conselho de Ensino, Pesquisa e Extensão (CEPE) está disponível na íntegra em <http://www.progepe.ufpr.br/concursos/editais/cepe1005.pdf >.
} 
Os autores também apontam questões éticas que emergiram da proliferação da literatura científica e foram impulsionados pela eminente necessidade de publicar: a "ciência salame" - na qual uma pesquisa é dividida para gerar vários artigos a serem publicados em revistas diferentes -, o "publicacionismo" e o "produtivismo" (CASTIEL; SANZ-VALERO; CYTED, 2007).

Nesse cenário os artigos são concebidos, segundo Castiel, SanzValero e Cyted (2007, p. 3045), "[...] como se fossem mercadorias que estarão disponibilizadas em revistas científicas". Os periódicos, no presente contexto, são seletivos tanto na esfera acadêmica (qualidade do estudo) como na esfera da oferta e da demanda (interesse dos editores e público-alvo da revista).

\section{Possibilidades de publicaÇão da Sociologia do ESPORTE}

Visto o lugar de destaque das publicações nas avaliações e na carreira acadêmica, apresentamos a seguir o cenário das possibilidades de publicação da Sociologia do Esporte. Na área da Educação Física, temos um total 865 periódicos. Nos estratos específicos que abordamos (A1 a B2) existem 498 periódicos. A maior parte desse recorte é destinada às Ciências Biológicas e demais áreas (467 revistas) e 31 periódicos possuem o escopo abrangente em que é possível a inserção da Sociologia do Esporte. Tais revistas estão distribuídas da seguinte forma:

\begin{tabular}{|c|c|}
\hline Qualis & Número de revistas \\
\hline A1 & 1 \\
\hline A2 & 1 \\
\hline B1 & 9 \\
\hline B2 & 20 \\
\hline
\end{tabular}

Figura 2 - Revistas da Educação Física em que é possível a inserção da Sociologia do Esporte

Fonte: Os autores (2011) 
Este cenário nos permite inferir que o universo de possibilidades de submissão dos pesquisadores da Sociologia do Esporte na Educação Física é objetivamente mais reduzido, ao ser comparado às possibilidades dos pesquisadores das Ciências Biológicas. Além do número reduzido de periódicos, também notamos que esses se encontram, na sua maioria, nos estratos mais baixos. Isso acarreta em uma desvantagem a esses pesquisadores, cujas produções são valoradas pelo sistema de avaliação apresentado e dentro de um campo em que a produção em periódicos é fundamental para o crescimento na carreira e na busca por financiamentos.

Dos números apresentados não foi possível acessar 4 revistas do extrato B2 pois os sites não estavam atualizados ou os periódicos não possuíam um endereço eletrônico. Das revistas consultadas não foram encontrados artigos sobre a Sociologia do Esporte em um periódico do estrato B1 e doze periódicos do estrato B2. Tais informações são apresentadas no quadro a seguir:

\begin{tabular}{|c|c|}
\hline Qualis & Número de revistas \\
\hline A1 & --- \\
\hline A2 & --- \\
\hline B1 & 1 \\
\hline B2 & 12 \\
\hline
\end{tabular}

Figura 3 - Revistas da Educação Física que não apresentaram artigos da Sociologia do Esporte

Fonte: Os autores (2011)

Quando lançamos o olhar para a área da Sociologia, percebemos um total 435 periódicos. Nos estratos específicos que abordamos (A1 a B2) existem 201 periódicos. Desse número, 135 revistas são focadas em temáticas específicas e em 66 periódicos seria possível publicar sobre a Sociologia do Esporte. Tais revistas estão distribuídas da seguinte forma: 


\begin{tabular}{|c|c|}
\hline Qualis & Número de revistas \\
\hline A1 & 15 \\
\hline A2 & 21 \\
\hline B1 & 11 \\
\hline B2 & 19 \\
\hline
\end{tabular}

Figura 4 - Revistas da Sociologia em que é possível a inserção da Sociologia do Esporte

Fonte: Os autores (2011)

As possibilidades de publicação nessa área se encontram em maior número, se comparada à Educação Física. Os pesquisadores dispõem de mais opções para publicação em estratos mais altos, sendo possível uma produção com maior relevância no sistema de avaliação vigente.

Não tivemos acesso à produção de 2 revistas do estrato A1, 1 periódico do estrato A2, 2 publicações do estrato B1 e 6 periódicos do estrato B2. Em nove periódicos do estrato A1, dezoito revistas do estrato A2, oito periódicos do estrato B1 e doze revistas do estrato B2 não existem publicações sobre a Sociologia do Esporte. Os dados estão compilados no quadro a seguir:

\begin{tabular}{|c|c|}
\hline Qualis & Número de revistas \\
\hline A1 & 9 \\
\hline A2 & 18 \\
\hline B1 & 8 \\
\hline B2 & 12 \\
\hline
\end{tabular}

Figura 5 - Revistas da Sociologia que não apresentaram artigos da Sociologia do Esporte

Fonte: Os autores (2011) 
Tais informações nos permitem pensar que apesar das possibilidades de publicação nos periódicos da Sociologia, não existe a divulgação de pesquisas da Sociologia do Esporte em um número significativo de revistas. Esta situação pode ser analisada nos termos da oferta e demanda das produções científicas, como mencionamos anteriormente, nos quais tal produto - o estudo sobre a Sociologia do Esporte - não possui demanda na área da Sociologia.

Ao considerar o número de artigos publicados por estrato, dada as condições acima citadas, temos a seguinte tabela:

\begin{tabular}{|c|c|c|}
\hline Qualis & \multicolumn{2}{|c|}{ Número de artigos } \\
\hline & Educação Física & Sociologia \\
\hline A1 & 1 & 10 \\
\hline A2 & 5 & 3 \\
\hline B1 & 46 & 1 \\
\hline B2 & 26 & 2 \\
\hline
\end{tabular}

Figura 6 - Número de artigos publicados por estrato Fonte: Os autores (2011)

Fica evidente a diferença numérica das publicações entre as áreas pois somam-se 78 publicações na Educação Física e apenas 16 artigos nos periódicos da Sociologia. Desse último, 12 são publicações em revistas internacionais e 4 artigos constam em periódicos nacionais. É significativo que a maior parte dos artigos publicados pertença a revistas internacionais, dando indícios de como o campo acadêmico e científico brasileiro se delineia.

\section{As "REGRAS DO JOGO": PUBLICAR OU PERECER}

Pierre Bourdieu estabelece, em seus estudos sobre o campo científico, noções que nos serão úteis para a análise dos dados levantados e seus indícios. Para o sociólogo francês (BOURDIEU, 
1983, 2004), o campo científico se constitui como um espaço social estruturado, no qual os agentes travam suas disputas por objetos de interesse. Dessa forma, o que orienta os pontos de vista, as intervenções científicas, os lugares de publicação, os temas escolhidos e os objetos que suscitam interesse é influenciado pela estrutura de relações objetivas entre os diversos agentes e instituições do campo. Essas relações de poder determinam historicamente o que é legítimo nesse espaço ou não.

Com a presente pesquisa, pudemos identificar que no campo da Educação Física a leitura sociológica do esporte não possui o mesmo espaço do que as interpretações baseadas nos fundamentos biológicos. O número de periódicos em que é possível publicar sobre a Sociologia do Esporte é consideravelmente menor do que o espaço editorial reservado para a publicação de estudos ligados às ciências biológicas.

Além do número reduzido de revistas, como demonstrado anteriormente, elas se encontram em estratos mais baixos no Qualis. Dessa forma, nos sistemas de avaliação apresentados, os pesquisadores estariam em condições desproporcionais em suas avaliações na área da Educação Física. A disputa pelos objetos de interesse - publicações, prestígio, legitimidade - apresenta-se desigual, explicitando quem são os dominantes e os dominados desse campo, bem como a tendência para a reprodução dessa ordem hierárquica.

Em relação ao campo da Sociologia, percebemos que os pesquisadores da Sociologia do Esporte possuem maiores possibilidades de publicação. Porém, isso não se concretizou no levantamento dos artigos. Foram mapeados 16 artigos nessas publicações, enquanto na Educação Física foram encontrados 78 artigos. A diferença é significativa e nos leva a cogitar que a entrada desses agentes no campo da Sociologia não ocorre sem resistências.

Além das interferências externas, o campo científico possui seus conflitos internos por ser um espaço onde lutas são travadas para conservá-lo ou modificá-lo e as relações de força e dominação são constantes. Ao se inserirem no campo da Sociologia, os 
pesquisadores da Sociologia do Esporte travam relações com os agentes "nascidos" nesse espaço social, portanto, legitimados no campo a partir de sua formação. Dessa maneira, a estrutura dessas relações sociais define as ações tomadas no campo como a escolha de objetos de pesquisa, os lugares de publicação dentre outras questões que fundamentam a consolidação de uma área de pesquisa. Se o esporte não ocupa uma posição privilegiada na hierarquia de objetos que os agentes desse campo determinaram, sua publicação obviamente não será frequente (BOURDIEU, 2004).

Bourdieu complementa tal análise quando sugere que os alvos mais importantes envolvidos nas lutas que se desenrolam no campo literário, com o qual podemos realizar uma associação com o campo científico, é a definição dos limites do campo e da participação legítima nas disputas. Comentar sobre uma corrente, definir o que é ou não é um trabalho científico, significa recusar existência legítima a esses objetos e excluí-los do jogo (BOURDIEU, 1990). Esse ostracismo simbólico é o inverso do esforço no sentido de impor uma definição que delimitaria a prática legítima, no sentido de construir uma definição do que seria científico. Tal delineamento atenderia aos interesses específicos dos detentores de um capital também específico, o capital científico.

Quando essa estratégia, que é tanto científica quanto política, e a competência que ela coloca em pauta apresentam sucesso, é possível atribuir a elas um poder sobre o capital detido pelos demais produtores. Assim, através da imposição de determinada prática legítima, é a regra mais favorável ao capital do dominante que acaba impondo aos demais o seu trunfo, ou seja, as suas realizações se tornam o parâmetro de todas as outras (BOURDIEU, 1990).

Com tais noções podemos pensar que a CAPES atua como uma instituição que possui legitimidade e capital suficiente para determinar - através da avaliação por pares, do impacto e demais formas apresentadas nesse artigo - o que é ou não ciência de qualidade. Dessa forma concebemos em um plano mais abrangente que existe uma tensão entre pesquisadores e a instituição no que concerne o sistema de avaliação (SCHWARTZMAN, 2011). 
Em outra esfera, percebemos que existem disputas entre os agentes que se debruçam sobre o esporte e os agentes da Sociologia. Nesse enfrentamento, normalmente os recém-chegados - os pesquisadores do esporte - tendem a estratégias de subversão, uma ruptura crítica, enquanto aqueles que, numa situação privilegiada no campo e que possuem mais capital específico, tendem a apresentar uma estratégia de conservação. Usualmente estas jogadas fazem com que o dominante saia do seu silêncio impondo o seu discurso, reiterando hierarquias e disposições, visando restaurar o equilíbrio no campo (BOURDIEU, 1983).

Existem vantagens para os que "nascem" no campo, como o domínio imanente das leis do campo não escritas, mas inscritas na realidade como tendências, ou seja, esses agentes entendem o "sentido do jogo" (BOURDIEU, 2004, p. 27). Ao compreender o "sentido do jogo" o agente é capaz de antecipar tendências, encontrando-se em vantagem em relação aos agentes que se inseriram no campo posteriormente. Bourdieu (2004, p. 28) afirma que:

Como um bom jogador de rugby sabe para onde vai a bola e se põe lá onde a bola vai cair, o bom cientista jogador é aquele que, sem ter a necessidade de calcular, de ser cínico, faz as escolhas que compensam. Aqueles que nasceram no jogo têm o privilégio do "inatismo". Eles não têm a necessidade de serem cínicos para fazer o que é preciso quando é preciso ganhar a aposta.

Sendo assim, podemos pensar que os pesquisadores da Sociologia do Esporte, pelo estado de emergência e consolidação da área/disciplina e ainda compreendendo parcialmente o "sentido do jogo", possuem dificuldades de inserir suas pesquisas em periódicos nacionais na área da Sociologia, fato que apresenta um cenário diverso em publicações internacionais. Essa abertura de revistas internacionais é pouco aproveitada por pesquisadores brasileiros não encontramos artigos desses autores nos referidos periódicos oportunidade que poderia contribuir para a melhor avaliação desses pesquisadores, já que tais revistas pertencem, em sua maioria, aos estratos A1 e A2. Cogitamos que tal situação seja catalisada por 
uma barreira linguística, já que tais publicações são em sua maior parte em inglês e francês, dificultando a inserção de pesquisadores brasileiros. Considera-se, igualmente, uma possível indisposição com alguns temas e análises localizadas, de pouca abrangência ou possibilidades comparativas em nível internacional e que acabam desinteressando os avaliadores dos periódicos.

\section{Algumas Considerações...}

Constatamos, por meio da investigação empírica, a dificuldade que a área de fronteira da Sociologia do Esporte enfrenta no processo de publicação científica. A grande questão é o diminuto espaço de publicação dentro dos periódicos classificados no Qualis para os pesquisadores das áreas humanas e sociais. Essa constatação converge para um problema: o processo inflexível de avaliação do sistema de Pós-Graduação no Brasil.

É verdade que o problema aqui colocado possui uma conotação bastante distinta. No entanto, a Educação Física, que é ainda uma "recém-chegada", está alocada e apresenta um papel menor em relação a áreas acadêmicas mais tradicionais.

A Educação Física, na esteira das mudanças em curso, adentrou no sistema, apesar da falta de tradição acadêmica e de problemas históricos como recursos financeiros escassos e autonomia limitada de temas e métodos. A inserção, ainda que de forma insipiente, ocorreu na década de 1980 e foi marcada pela tentativa tardia da área na definição de seu objeto de estudo e, por extensão, na obtenção do status científico, principalmente, com a importação de teorias desenvolvidas em outros centros.

Considerando a tradição acadêmica da Educação Física, tornase difícil pensar que a área tenha condições de nivelamento em curto ou médio prazo. Assim, o espaço imposto é exterior e os critérios estabelecidos restritivos.

A Sociologia do Esporte, essa parcela recente de uma área com uma variedade epistemológica que as distingue das demais, 
acaba por se configurar como uma disciplina com menor espaço e ainda em processo de consolidação, fato que pode ser percebido no perfil de publicações apresentado nesse artigo.

Quando consideramos a emergência da Sociologia do Esporte na área da Sociologia, é notória sua condição de "recém-chegada" procurando inserção em periódicos bem qualificados. Todavia o cenário nacional ainda não se mostra favorável a tais contribuições, limitando assim a circulação do conhecimento e dos pesquisadores da área.

Dessa forma, pode-se supor que pode estar ocorrendo uma deformação da área produzida pela subserviência às grandes áreas. A mudança esperada a longo prazo é a obtenção do status científico pela visão ampliada das contribuições que tais estudos possam render à sociedade. A Sociologia do Esporte, que deveria ser caracterizada pelo que se está produzindo nos meios acadêmicos, acaba por não possuir um espaço consolidado e, como uma área de fronteira, sofre as consequências dessa crise de identidade no processo de avaliação.

O processo é dinâmico, o balanço do poder está sendo determinado por um grupo de pesquisadores que fazem parte do Conselho Técnico Científico (CTC) da CAPES - como podemos perceber pelos instrumentos avaliativos apresentados aos quais os agentes são submetidos periodicamente em suas carreiras e, de acordo com Schwartzman (2008), que destaca o caráter impositivo de tais avaliações e sua deficiência para adaptar-se às mudanças do cenário acadêmico - que em contraposição a outros grupos, legitimam seus espaços e, a princípio, são anuentes com a situação. Trata-se de uma visão supostamente reducionista, que desconsidera e, por que não dizer, desrespeita a área, sua história e o que é produzido.

Algumas áreas conseguiram avanços significativos e inserção internacional, como a área de História do Esporte e da Educação Física, por exemplo. No entanto, como prega o modelo de avaliação de cada área, é preciso existir uma ligação com a área básica, sob o risco de ser preterido. Schwartzman (2008, p. 11) alerta que essa dificuldade de avaliação de áreas interdisciplinares é uma das falhas 
desse sistema proposto pela Capes que possui "dificuldade em lidar com áreas novas, ou interdisciplinares, que não se enquadram facilmente nos moldes das disciplinas mais tradicionais e institucionalizadas". A questão da posição do objeto de estudo na hierarquia posta nas áreas da Sociologia e da Educação Física também se torna restritiva uma vez que no "mercado" de produções científicas, as leis de oferta e demanda acabam por sobrepujar a produção e circulação das ideias no campo acadêmico e científico. Sendo assim, torna-se uma tarefa delicada e árdua para o pesquisador da Sociologia do Esporte ter seus trabalhos publicados, o que consequentemente acarreta na dificuldade de acesso a bolsas fornecidas pelas agências de fomento e afeta suas classificações em concursos públicos, se abordarmos algumas das questões objetivas da avaliação. Outra questão também a ser pensada é a visibilidade que esses pesquisadores obtêm no campo acadêmico em que atuam, uma vez que a produtividade está atrelada ao estabelecimento de um nome, um símbolo, a questões de prestígio e distinção (BOURDIEU, 2004, 2007).

Para finalizar destacamos que o presente artigo - que se pretende uma abordagem inicial - não tem como meta esgotar a discussão proposta. Uma vez notada a escassez de referências sobre o referido cenário, esperamos ter contribuído para um melhor entendimento das dinâmicas do campo acadêmico e científico em que se insere a Sociologia do Esporte buscando avanços nesse âmbito de debate e também estimulando novas produções. 


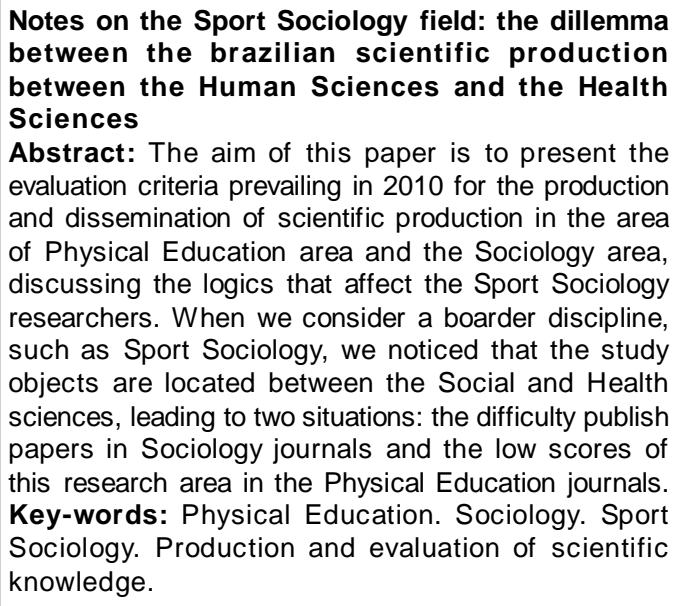

Abstract: The aim of this paper is to present the evaluation criteria prevailing in 2010 for the production and dissemination of scientific production in the area of Physical Education area and the Sociology area, discussing the logics that affect the Sport Sociology researchers. When we consider a boarder discipline, such as Sport Sociology, we noticed that the study objects are located between the Social and Health sciences, leading to two situations: the difficulty publish papers in Sociology journals and the low scores of this research area in the Physical Education journals. Key-words: Physical Education. Sociology. Sport Sociology. Production and evaluation of scientific knowledge.

Notas sobre el campo de la Sociología del
Deporte: el dilema de la producción científica
brasileña entre las Ciencias Humanas y de la
Salud
Resumen: El objetivo del trabajo es presentar los
criterios de evaluación vigentes en 2010 para la
producción y difusión de la producción científica en el
área de Educación y Sociología, discutiendo las lógicas
que afectan a los investigadores de la Sociología del
Deporte. Cuando se considera esta disciplina de
frontera, percibimos que los objetos de estudio se
encuentran entre las Ciencias Sociales y de la Salud,
causando el enfrentamiento de estas dos situaciones:
la dificultad de inserción de los artículos en revistas
científicas de Sociología y las puntuaciones bajas en
la línea de investigación en las revistas de Educación
Física.
Palabras clave: Educación Física. Sociología.
Sociología del Deporte. Producción y Evaluación de
los Conocimientos Científicos.

\section{REFERÊNCIAS}

ALABARCES, P. Veinte años de Ciencias Sociales y deportes, diez años después. Revista da ALESDE, Curitiba, v. 1, n. 1, p. 11-22, set. 2011.

ASSUMPÇÃO L. et al. Temas e questões fundamentais na Sociologia do esporte. Revista Brasileira de Ciência e Movimento, Brasília, v. 18, n. 2, p. 92-99, abr. 2010.

ovimento, Porto Alegre, v. 19, n. 02, p. 251-275, abr/jun de 2013. 
BETTI, M. A janela de vidro: esporte, televisão e Educação Física. Campinas, Papirus, 1998.

BOURDIEU, P. Coisas ditas. São Paulo: Brasiliense, 1990.

A distinção: crítica social do julgamento. São Paulo: Edusp, 2007.

Questões de sociologia. Rio de Janeiro: Marco Zero, 1983.

Os usos sociais da ciência: por uma sociologia clínica do campo científico. São Paulo: UNESP, 2004.

CASTIEL, L.; SANZ-VALERO, J.; CYTED, R. Entre fetichismo e sobrevivência: o artigo cientí?co é uma mercadoria acadêmica? Cadernos de Saúde Pública, Rio de Janeiro, v. 23, n. 12, p. 3041-3050, 2007.

COAKLEY, J. Sports in society: issues and controversies. New York: McGrawHill, 2009.

COORDENAÇÃO DE APERFEIÇOAMENTO DE PESSOAL DE NÍVEL SUPERIOR. Avaliação da Pós-graduação. Disponível em: <http://www.capes.gov.br/ avaliacao/avaliacao-da-pos-graduacao>. Acesso em: 2 ago. 2011 a.

Avaliação periódicos Capes. Disponível em: <www.capes.gov.br/ avaliacao/qualis>. Acesso em: 8 jul. 2011b.

Avaliação Trienal dos Programas de Pós-graduação. Disponível em: <www.trienal.capes.gov.br>. Acesso em 8 jul. 2011c.

2011d.

Página inicial. Disponível em: <www.capes.gov.br>. Acesso em: 8 jul.

GASTALDO, E. Estudos Sociais do Esporte: vicissitudes e possibilidades de um campo em formação. Logos, Rio de Janeiro, v. 17, n. 2, jul. 2010.

LUZ, M. Prometeu Acorrentado: análise sociológica da categoria produtividade e as condições atuais da vida acadêmica. Revista Saúde Coletiva, Rio de Janeiro, v. 15, n. 1, p. $39-57,2005$.

MARCHI JUNIOR, W.; CAVICHIOLLI, F. Diagnóstico da Sociologia do Esporte no Brasil: para a consolidação de um campo de conhecimento. In: CORNEJO, M.; MARCHI JUNIOR, W. (Org.). Estudios y Proyectos em Sociología del Deporte y la Recreación em América Latina. Concepción: Trama Impresores, 2008. p. 102-112.

MARCONI, M. de A.; LAKATOS, E. M. Metodologia científica. 3. ed. São Paulo: Atlas, 2000.

MEDEIROS, C.; GODOY, L. As referências de Pierre Bourdieu e Norbert Elias na Revista Brasileira de Ciências do Esporte: mapeando tendências de apropriação e de produção de conhecimento na área de Educação Física (1979- 
2007). Revista Brasileira de Ciências do Esporte, Campinas, v. 30, n. 2, p. 1-12, jan. 2009.

MEDINA, João Paulo. A Educação Física cuida do corpo... e "mente". 10. ed. Campinas: Papirus, 1992.

MOREIRA, W. (Org.). Educação Física \& esportes: perspectivas para o século XXI. Campinas: Papirus, 1992.

MURAD, M. Sociologia e Educação Física: diálogos, linguagens do corpo, esportes. Rio de Janeiro: FGV, 2009.

PILATTI, L. A.; MARCHI JÚNIOR, W., VLASTUIN, J. Physical Education Research in Brazil: post-graduation ways and detours. STAPS - Revue Internationale des Sciences du Sport et de l'éducation phisique, Montpellier, v. 30, n. 85, p. 7184, 2009.

SCHWARTZMAN, S. Ciências naturais, ciências sociais e humanidades: com um adendo sobre a necessidade de rever o sistema de avaliação da CAPES. Disponível em <bit.ly/pQJUHc>. Acesso em: 30 jul. 2011.

SOUZA, J.; MARCHI JÚNIOR, W. Por uma Gênese do Campo da Sociologia do Esporte: cenários e perspectivas. Movimento, Porto Alegre, v. 16, n. 2, p. 45-70, abr./jun. 2010.

TOLEDO, L. Futebol e Teoria Social: aspectos da produção científica brasileira (1982-2002). Revista Brasileira de Informação Bibliográfica em Ciências Sociais, São Paulo, v. 2, n. 52, p. 133-155, jul. 2001.

UNIVERSIDADE FEDERAL DO PARANÁ. Conselho De Ensino, Pesquisa e Extensão. Resolução no 10/05. Disponível em: <http://www.progepe.ufpr.br/concursos/ editais/cepe1005.pdf> Acesso em: 10 jul. 2011.

Endereço para correspondência:

Ana Leticia Padeski Ferreira

Rua Guilherme Seeger, 580. Curitiba - PR.

CEP: $80520-420$

Recebido em: 10.10.2012

Aprovado em:22.01.2013 